\title{
Strategic Partnerships of Universities as a Tool for Intensifying the Development of the Regional Economy and Society in Digital Economy
}

\author{
Alexander Tarasov \\ International Administration \\ National Research University "Moscow Power Engineering \\ Institute" \\ Moscow, Russia \\ TarasovAY@mpei.ru \\ Ekaterina Sysoeva \\ Department of International Relations \\ National Research University "Moscow Power Engineering \\ Institute" \\ Moscow, Russia \\ SysoyevaYekA@mpei.ru
}

\author{
Elena Gulicheva \\ Department of International Relations \\ National Research University "Moscow Power Engineering \\ Institute" \\ Moscow, Russia \\ GulichevaYG@mpei.ru \\ Mai Nguyen Tuyet Hoa \\ Office of Research and Partnership Development \\ Vietnam National University \\ Hanoi, Vietnam \\ hoamnt@isvnu.vn
}

\begin{abstract}
The article is devoted to topical issues of strategic partnership of universities with subjects of regional economy and society in digital economy. An overview of the tools for effective strategic partnership of universities at the regional level in digital economy, which can be used for its individual positioning, is given. The tools were developed taking into account the needs and capabilities of the existing regional ecosystem. The system of regional development and synergetics of its components is considered from the position of a university, as one of the key "players" in order to optimally build process models of individual bilateral partnerships. Integration of regional universities leads to increase in educational potential and consolidation of the entire regional community. This will increase the effectiveness of the regional higher education system through the formation of a unified educational space, integrated marketing, scientific unity, and an integrated business education system. Strategic partnership of enterprises belonging to territorial production clusters with universities and leading research centers allows making new discoveries, creating innovations, knowledge, training highly qualified specialists, and also contributes to stable economic growth and competitiveness of a region in digital economy. It also needs to take into account the speed of rapid technological development, the growing demand for more flexible digital ecosystems and effective strategic solutions to manage the digital future.
\end{abstract}

Keywords—strategic partnership, digital economy, regional economy, clusters, competencies, education, coronavirus infection.

\section{INTRODUCTION}

The global community is experiencing a trend characterized by the struggle for strategic intellectual resources. This situation appeared due to the fact that in the modern world theoretical and practical knowledge become factors of production, including in the field of digital economy [1]. The processes of knowledge creation and dissemination form an integral system organically integrated into the economic activities of firms, regions, and national governments [2]. To achieve advantages in this direction, the right vector of highly competitive strategic development is necessary to choose, as well as to form tools and management mechanisms leading to the achievement of a specific goal [3].

In the modern world, digitalization permeates all spheres of economy. The use of new technologies accelerates processes and operations, reduces the organization's costs and increases its efficiency [4]. Thus, the use of digital technologies increases the competitiveness of organizations [5].

Enterprises and countries able to take advantage of the opportunities of digital technologies in time will become providers of innovative solutions and gain a significant advantage over other players, including at the international level.

Taking into account the importance and prospects for the development of digital economy in Russia, where digital data is a key factor of production in all spheres of social and economic activity, the President of Russia set the task [6] to ensure the accelerated introduction of digital technologies in the economy and social sphere. In order to solve this problem, a national program "Digital Economy" has been developed [7].

Today, the strategic development of the region is undoubtedly impossible without the uniform development of the main subjects of socio-economic activity on its territory. The development of a system of optimal interaction between business clusters, government bodies, the educational community, scientific schools and non-profit sector in the region will provide promising synergy for the development of the territory, its competitiveness in the modern investment and labor market. 
The main goal of the study is to build process models for individual bilateral partnerships.

The target of the study is to consider the system of regional development and the synergy of its components from the position of a university as one of the key "players".

The research is based on the following methods: dialectical scientific cognition and particular scientific ones, such as analysis, comparison, synthesis, system-structural and logical analysis, formalization, analysis of regulatory documents, modeling.

\section{STRATEGIC PARTNERSHIP AT THE REGIONAL LEVEL}

Strategic partnership is a formalized alliance between two or more higher education institutions or other organization, created as a result of a deliberate process when partners share resources and use additional strengths to achieve certain common goals [8]

In order to determine the direction and main parameters of strategic regional development, or determine the goals of various strategic partnerships at the regional level, it is necessary to know the starting point. In this regard, a systematic approach to the analysis of multilateral territorial cooperation is applied. Within the framework of a systematic approach, process models of individual bilateral partnerships have been built.

For each model the following elements are defined:

- inputs - resources for effective existence and development of partnerships;

- control flows - regulatory framework for partnership development, legislative and internal restrictions;

- mechanisms - institutional mechanisms for the implementation of partnerships in the region;

- outputs - self-strategic development of partnership and strategic development of the region at the highest level of the model.

A region-oriented top-level model is decomposed according to the rules of structural modeling into five models.

The top-level model - "University $\leftrightarrow$ Strategic Partner", is aimed at long-term cooperation by creating sustainable academic networks, strengthening student and staff exchanges, knowledge and practices.

Considering the implementation mechanisms and the resource base of strategic partnerships, it is necessary to consider the predicted limitations (counteractions) of their implementation at the first stage. This factor gives the research a vector for continuation.

The strategic development of the region is impossible without the sustainable development of the main subjects of social and economic activity.

The main subjects include representatives of higher education institutions, legislative and executive authorities at all levels, non-profit organizations, science and innovation organizations, enterprises and entrepreneurs. The straight arrow shows the strategic partnership between the entities, and the dashed arrow shows financial flows (Fig. 1).

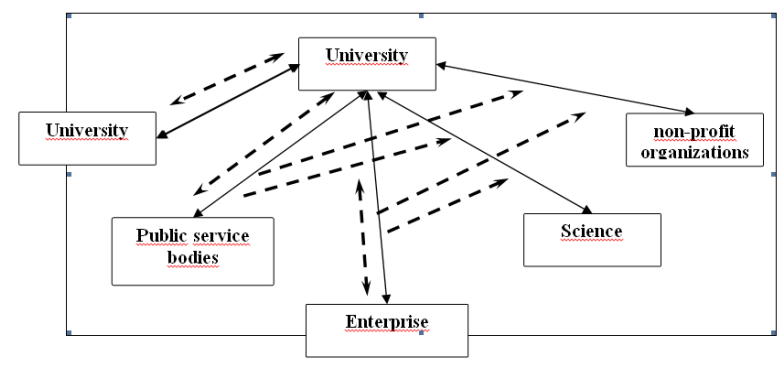

Fig. 1. Strategic partnership in the region.

Source: developed by the authors

In order to determine the direction and main parameters of strategic regional development or the goals of various strategic partnerships at the regional level - it is necessary to know the starting point!

Strategic regional partnership at the input is influenced by:

- prerequisites for the formation;

- financial resources;

- human resources;

- administrative resources;

- information resources and infrastructure.

Control flows include predicted regulatory, institutional and social constraints. Institutional implementation mechanisms are also affected.

As a result, we get the strategic development of the region and, accordingly, all the subjects of partnership. What the strategic partnership model is.

Ideally, when considering the implementation mechanisms and resource base of strategic partnerships, it is necessary to start from the projected limitations (obstacles) to their implementation.

\section{MODEL "STRATEGIC PARTNERSHIP "UNIVERSITY $\leftrightarrow$ PUBLIC SERVICE BODIES"}

The model "Strategic partnership "University $\leftrightarrow$ Public service bodies" is aimed at forming a personnel reserve to ensure the implementation of programs for the socioeconomic development of a region; examination of municipal and regional programs of social and economic development and participation in its development; scientific support of socio-economic development programs of a region.

Sustainable innovation and digital development of a region are the main goal of the partnership.

Resources affecting the model:

- financial resources, for example, grant programs; targeted budget programs;

- personnel, for example, academic staff, graduate students, practitioners from the administration;

- $\quad$ administrative resources, for example, management decisions;

- $\quad$ informational resources (mass media);

- infrastructural resources, such as administration structure and a university infrastructure.

Limitations:

- $\quad$ inert personnel rotation system; 


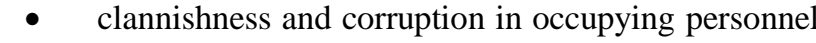

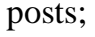

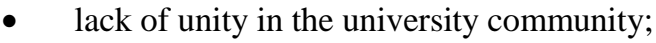

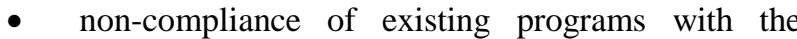

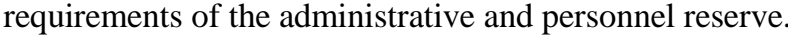

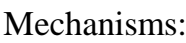

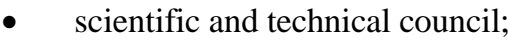

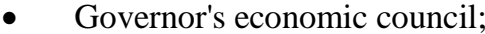

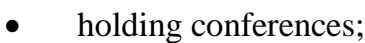

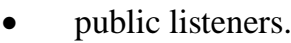

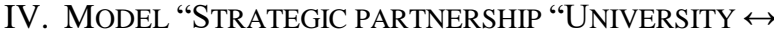

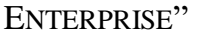

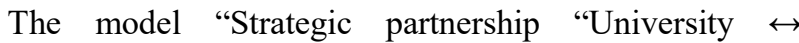

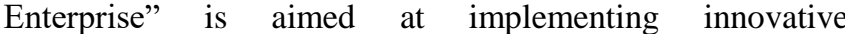

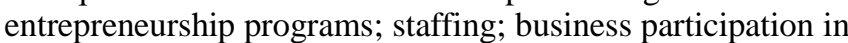

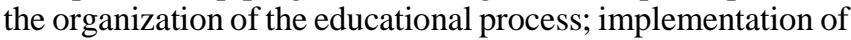

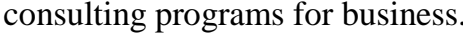

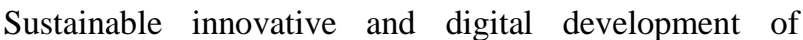

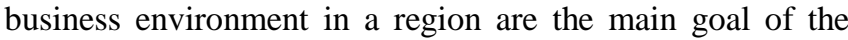

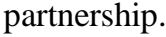

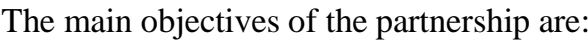

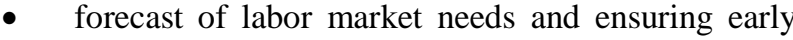

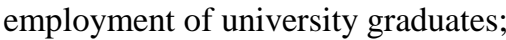

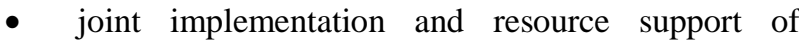

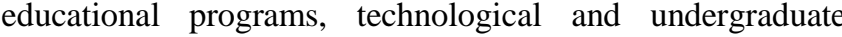

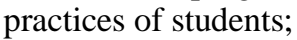

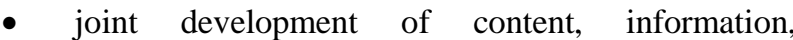

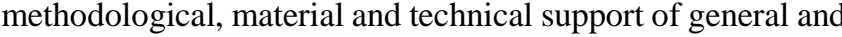

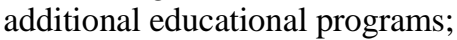

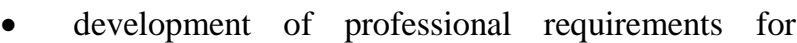

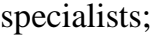

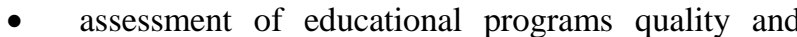

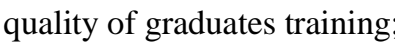

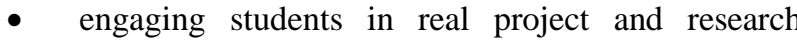

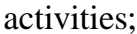

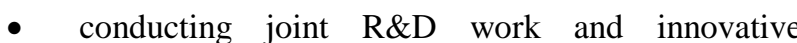

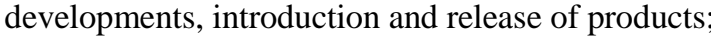

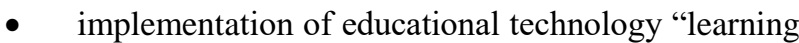

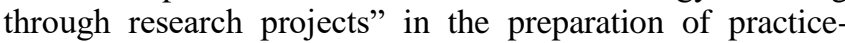

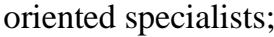

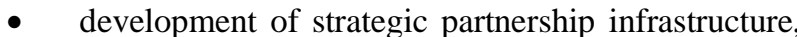

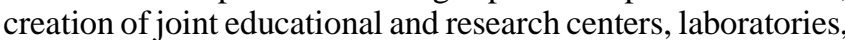

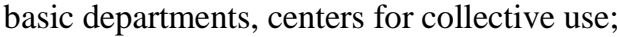

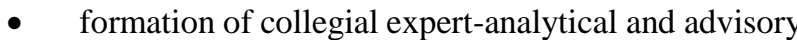

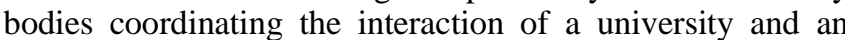

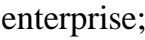

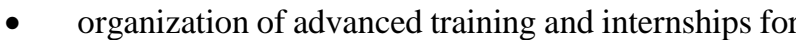

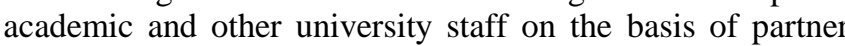

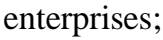

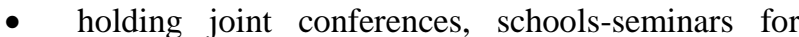

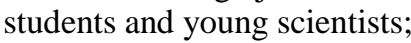

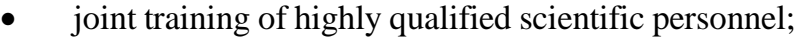

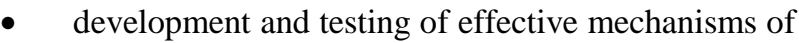

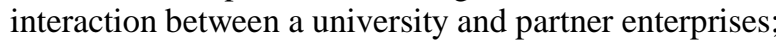

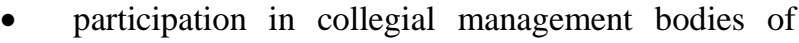

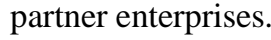

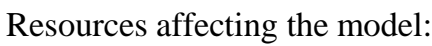

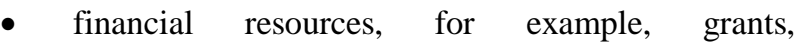

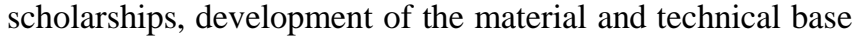

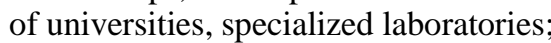

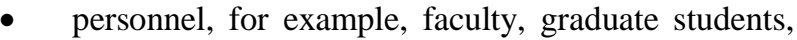

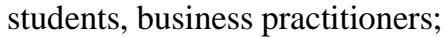

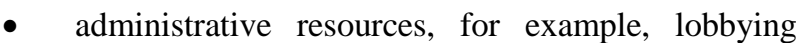

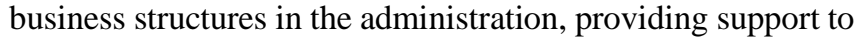

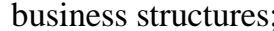

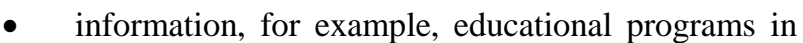

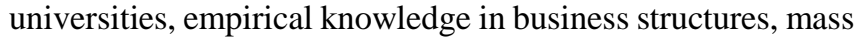

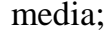

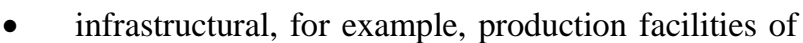

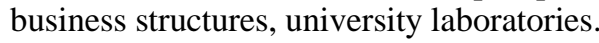

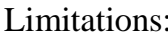

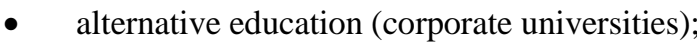

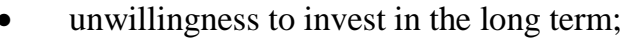

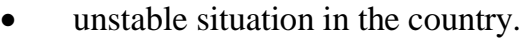

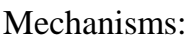

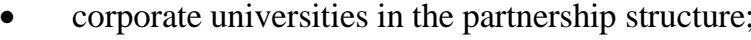

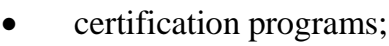

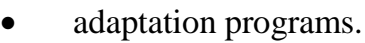

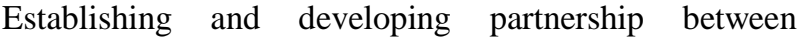

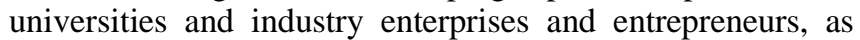

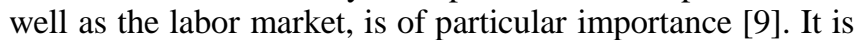

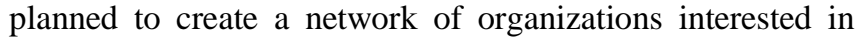

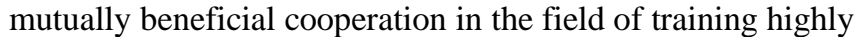

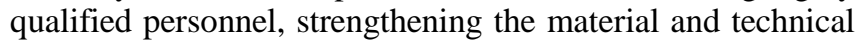

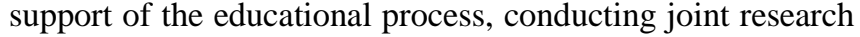

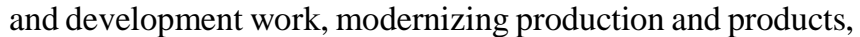

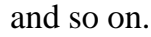

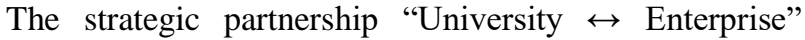

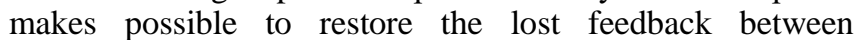

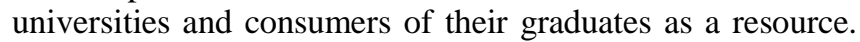

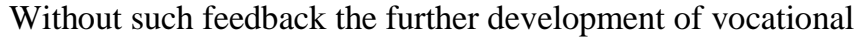

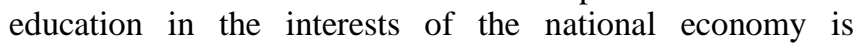

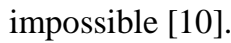

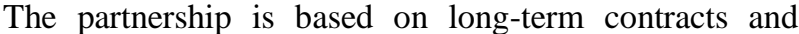

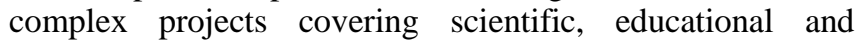

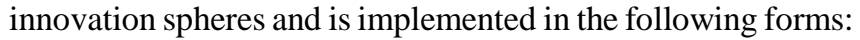

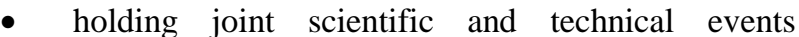

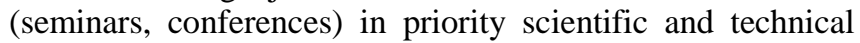

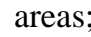

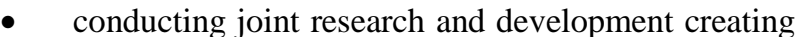

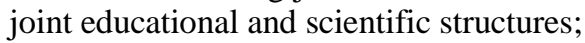


- $\quad$ organization of internships and graduate projects of students in a partner organization;

- $\quad$ targeted training of specialists ordered by a partner organization;

- $\quad$ retraining and advanced training of specialists of the partner organization by the academic staff of a university;

- $\quad$ participation in the formation of training plans and work programs for specialists;

- $\quad$ using the scientific, technical and human resources potential of a partner organization in the educational process;

- training of partner organization employees at the university $\mathrm{PhD}$ courses.

\section{MODEL "STRATEGIC PARTNERSHIP "UNIVERSITY $\leftrightarrow$ SCIENCE"}

The model "Strategic partnership "University $\leftrightarrow$ Science" is aimed at creating laboratories and departments in research institutes; involvement of students in scientific activities; practical orientation of science.

Unity of university and academic science to improve the quality of the educational process is the main goal of the partnership.

Resources that affect the model:

- $\quad$ personnel, for example, graduate students, faculty, researchers;

- financial resources, for example, financial benefits from science, technological entrepreneurship;

- $\quad$ administrative resources, for example, joint impact of the scientific and educational community on the administrative bodies decisions and communications;

- information, for example, mass media, libraries, information bases of scientific and educational institutions;

- infrastructural resources, for example, material and technical base of educational and scientific institutions.

Limitations:

- $\quad$ different departmental affiliations;

- $\quad$ human factor;

- leveling the traditions of science in the educational sphere; tools.

- lack of sustainable intellectual property management

Mechanisms:

- joint scientific schools;

- joint research centers;

- programs for the intensification of scientific activities in universities;

- $\quad$ holding forums, conferences, symposia;

- $\quad$ joint postgraduate and doctoral studies;

- councils.
Activating the processes of forming educational trajectories aimed at developing competencies increases the competitiveness of industry and business in a region.

\section{MODEL "STRATEGIC PARTNERSHIP "UNIVERSITY $\leftrightarrow$ UNIVERSITY"}

The model "Strategic partnership "University $\leftrightarrow$ University" is aimed at the development of interuniversity cooperation, including in the international sphere; creation of joint projects.

Rational use of key competencies, such as: personnel, infrastructure, scientific schools, communications, resources is the main goal of the partnership.

Resources affecting the model:

- financial resources, for example, rational use of available resources, joint grants;

- $\quad$ personnel, for example, academic staff;

- $\quad$ administrative, for example, the use of joint relations in the administration of different levels;

- $\quad$ information, for example, scientific and educational bases of universities and partners;

- infrastructural, for example, the Council of Rectors, creation of joint innovation parks, infrastructure of two universities.

Limitations:

- $\quad$ competition between universities;

- $\quad$ unprepared legislative base;

- $\quad$ high degree of interpenetration of professors between universities (in small towns).

Mechanisms:

- $\quad$ joint educational programs;

- joint innovation and scientific programs;

- joint research laboratories;

- joint scientific schools.

A person develops and forms new competencies throughout life. The structure of the competence includes the following elements: theoretical and practical knowledge, skills and abilities [11]. A university is a space where key competencies of students are formed. An important condition for the development of students' skills in the field of digitalization is the availability of professional academic staff [12].

Development of digital competencies among the population allows to increase productivity, industry cooperation based on the needs of the environment [13]. However, in the regions, some problems the regional digital competence strategy faces still exist. For example, the growing uncertainty surrounding its general environment, including economic, social, political, environmental and technological factors is among these problems [14].

One of the leading directions of strategic cooperation between universities is the academic mobility of students, graduate students, young scientists and teachers, which allows 

1. The federal state of Brandenburg provides an opportunity for everyone who has passed the competition to study at the Brandenburg University of Technology (BTU) Cottbus - Senftenberg in Germany under the STUDEXA program for one or two semesters.

Brandenburg University of Technology is a fairly young university. It provides over 70 programs for undergraduate, graduate and postgraduate studies. At the moment, 7600 students study at the Brandenburg University of Technology, $26 \%$ are foreigners. The university provides a number of programs in the areas of cyber-physical systems, energy efficiency, environmental protection, bioengineering, management, medicine and art. The central dormitory of the university is located between Berlin and Dresden [21].

The main requirements for candidates who want to participate in the competition for participation in the "STUDEXA" program: proficiency in English or German (at least B2 level); high academic performance and others).

Funding is an important factor for participation in international academic programs. The "STUDEXA" program provides free training for the students and the participant covers the remaining expenses independently or attracts cofinancing from other sources.

MPEI students actively participate in the "STUDEXA" program. They won competition for training in 2018 and 2020 .

2. The federal state of Saxony provides an opportunity for students from many European countries, including Ukraine and Belarus, to receive a Georgius-Agricola-Stipendium scholarship since 2004. Scholarships are awarded for study or writing a scientific thesis at any university in Saxony.

Dresden Technical University is part of the association of the largest technical universities in Germany "TU 9". It is one of the oldest technical universities in Germany. In terms of number of students, Dresden Technical University ranks first among the technical universities in Germany. In 2010, it provided 60 such grants.

MPEI students won grants for studying under the Georgius-Agricola-Stipendium in 2015 and 2016.

3. The Bavarian Academic Center for Central, Eastern and Southeastern Europe, located in the federal state of the Free State of Bavaria, invites students from Bulgaria, Croatia, Hungary, Czech Republic, Romania, Poland, Russia, Slovakia, Serbia and Ukraine to participate in the annual Bayhost scholarship program. The scholarships are intended to fund the study and internship of masters and postgraduates at Bavarian universities. The annual scholarships can be renewed twice for up to 3 years.

In Russia, an example of a regional strategic association is the Association of Vice-Rectors for International Relations of Higher Educational Institutions of St. Petersburg; Association of universities of the South of Russia and others. Universities are united within the region to work together to be developed in the field of international activity.

Integration of regional universities leads to an increase in educational potential and consolidation of the entire regional community. This will increase the effectiveness of the regional higher education system through the formation of a unified educational space, integrated marketing, scientific unity, and an integrated business education system. Such associations help to find an better integrated approach to strategic cooperation at the regional level.

\section{CONCLUSION}

The creation of a single integrated educational space that interacts with all strategic partners, uniting all forms of education from kindergarten to retirement age and beyond, is key in the development of a region in digital economy.

As the international experience of most Russian universities shows, at present a common strategy for promoting the regions for all participants in foreign economic activity is practically necessary. Ideally, the individual positioning of each institution should take into account the needs and capabilities of the existing ecosystem. In order to successfully compete in the context of globalization and the rapidly changing geopolitical environment, regions need to develop missing competencies and effectively use the available limited resources. It also needs to take into account the speed of rapid technological development, the growing demand for more flexible digital ecosystems and effective strategic solutions to manage the digital future.

\section{REFERENCES}

[1] M. Dezuanni, M. Foth, K. Mallan, H. Hughes, Digital Participation through Social Living Labs, Chandos Publishing, 2017, 382 p.

[2] Passport of the national program "Digital Economy of the Russian Federation" (approved by the Presidium of the Council under the President of the Russian Federation for Strategic Development and National Projects, Protocol No. 16 of 24.12.2018)]. URL: http://www.consultant.ru/document/ cons_doc_LAW_319432/ (accessed 15.11.2020).

[3] N.V. Pelikhov, A.I. Bogush, V.D. Bykova, et al., "On the place and role of the professional and expert community in the management of international cooperation in Russian universities", Collective monograph "Modern problems and prospects for the internationalization of Russia's intellectual resources (challenges, strategies, models, interests of national, regional and sectoral development)", Moscow, RIOR, 2019, pp. 91-100.

[4] The strategy for the development of the information society of the Russian Federation for 2017-2030, approved by the Decree of the President of the Russian Federation of 09.05.2017, No. 203. URL: http://kremlin.ru/acts/bank/41919 (accessed 11.11.2020).

[5] A. N. Andreeva, E. M. Mizova, "Digital economy: new business opportunities", Economy and Business, 2018, vol. 4, pp. 19-21.

[6] Decree of 05.07.2018 "On national goals and strategic objectives of the development of the Russian Federation". URL: http://www.kremlin.ru/acts/bank/43027 (accessed 21.10.2021).

[7] Federal project "Human Resources for the Digital Economy". URL: https://digital.gov.ru (accessed 13.11.2020).

[8] N. Sh.Vatolkina, O. P. Fedotkina, "International strategic partnership of the university: interaction models", "Higher education in Russia", 2018, vol. 27 (6), pp.113-119.

[9] S. A. Atroshchenko, N. F. Geets, E. A. Gorshkov, et al., Problems and prospects for the development of science and education in modern conditions, Petrozavodsk, 2019, 260 p.

[10] N. V. Pelikhov, N. R Toivonen, E. A Knyazev, et al., Entrepreneurship and transformation of Russian universities, Rostov-on-Don, 2003. $272 \mathrm{p}$

[11] E. A. Sysoeva, N. L. Ketoeva, M. A. Kiseleva, et al., "Academic mobility of a student as a factor in the formation of key competencies of a graduate in the digital economy", Economics and Entrepreneurship, 2020, no. 8, pp. 1297-1301.

[12] S. V. Avilkina, M. A. Bakuleva, N. P. Kleynosova, "Development of methodology for assessing digital competence levels in personnel training", Economics, vol. 12 (2), 2019. pp. 40-51.

[13] P. Tumbas, M. Sakal, V. Pavlicevic, et al., Digital Competencies in Business Informatics Curriculum Innovation, 13th International 
Technology, Education and Development Conference, Valencia, Spain, 2019, pp. 9655-9664.

[14] K. Alam, Md. Shahiduzzaman, B. Ryan, et al., "Assessing regional digital competence: Digital futures and strategic planning implications", Journal of Rural Studies, vol. 60, 2018, pp. 60-69.

[15] E. A. Sysoeva, E. G. Gulicheva, Attracting students to university through academic mobility in digital economy, IX International Forum of Young Scientists Youth in Science and Entrepreneurship, Gomel, Republic of Belarus, 2020, pp. 408-410.

[16] E. A. Sysoeva, N. L. Ketoeva, "Development of information competencies in subjects of educational activities in digital economy during a pandemic of a new coronavirus infection", Economics and Entrepreneurship, no. 6, 2020, pp. 1316-1319.

[17] E. I. Kushnikov, A.V. Rodionova, Cluster approach in innovative development of regions: trends and prospects, Materials of the XI Annual All-Russian Conference and the XXI Annual All-Russian School-Seminar, Integration of Russian universities into the world educational and scientific space, taking into account regional characteristics, Rostov-on-Don, 2013, pp. 126-130.

[18] A. V. Zarkovich, N. V. Pelikhov, "Cluster approach to the formation of regional innovation systems (on the example of the Belgorod region)", Economics, entrepreneurship and law, vol. 2, no. 6, 2012, pp. 9-22.

[19] N. V. Pelikhov, E. I. Kushnikov, "Clusters and innovation systems: selection of indicators for calculating efficiency", Fundamental Research, no. 12-1, 2019, pp. 147-153.

[20] A. R. Groshev, N. V. Pelikhov, "Cluster initiatives: systemic features of formation, development and management", Journal of Leadership and Management, vol. 2 (2), 2019, pp. 91-106.

[21] Official site of the Studexa program at the Brandenburg Technical University. URL: b-tu.de/en/international/outgoing exchange/students -going-abroad/studexa (accessed 20.11.2020). 